\title{
Research on the Management of Temporary Employee in Universities' Logistics under the New Situation
}

\author{
Yang Li, Chen Yao* \\ North China Electric Power University,Logistics Management Office, Beijing,China \\ North China Electric Power University, School of Humanities and Social Sciences,Beijing,China \\ 13911993333@139.com,1120869327@qq.com \\ ${ }^{*}$ Chen Yao
}

Keywords: Universities' logistics, Temporary employee, Post management

\begin{abstract}
With the continuous deep developing of socialized reform in rear service at colleges and universities, temporary employee is becoming more and more strong. To strengthen the high-efficiency management of this group is relative to improvement of service quality and efficiency in universities' logistics department. However, there are some problems in the management of temporary employee at logistics department of colleges and universities, such as imperfect management system, unreasonable allocation of staff and other issues, etc. In order to achieve the optimal allocation of human resources, it is imperative to implement post management, improve the system, optimize the structure, and exploit the potential efficiency.
\end{abstract}

\section{新形势下高校后勤非在编员工管理研究}

\author{
杨利，陈圭 \\ 华北电力大学后勤管理处, 北京, 中国 \\ 华北电力大学人文与社会科学院, 北京, 中国 \\ 13911993333@139.com,1120869327@qq.com
}

陈圭

关键词: 高校后勤;非在编员工; 岗位管理

中文摘要. 随着高校后勤社会化改革的不断深入, 后勤非在编职工队伍不断壮大, 加强对非 在编职工的高效管理, 直接关系到高校后勤的服务质量与效率的提高。而高校后勤非在编职 工在管理中存在的管理制度不完善、人员配置结构不合理等问题, 需要通过岗位管理的实施, 完善制度、优化结构、挖潜增效, 实现后勤人力资源的优化配置。

\section{1. 引言}

社会化改革使高校后勤逐步探索形成了一种既符合办学规律又能适应社会主义市场经济 的新型人事制度体系, 企业化管理的实行和非在编员工的大量引入解决了高校后勤人力资源 管理的瓶颈, 实现了管理水平和服务质量的大幅提高。但面对高等教育日新月异的发展形势, 目前多数高校后勤员工队伍还难以适应现代大学建设的需要, 如何实现对高校后勤队伍管理 的优化, 已经成为摆在高等教育管理者面前的重要课题。[1] 


\section{2. 高校后勤非在编员工管理现状}

\section{1 顶层设计缺乏, 制度建设亟待完善}

1、管理制度片面性、临时性较强，缺乏体系。目前各高校人资管理方面的文件，大都是 针对在编员工, 而适用于非在编职工管理的规章制度, 散见于各个用人单位自行制定的临时 办法, 同一高校中非在编员工的考核、薪酬、管理方式大相径庭, 不仅缺乏同一有效的管理 部门，更缺乏系统而完善的制度体系。

2、员工发展受限，系统且有针对性的人员培训制度缺失。合理的人才发展机制尚未形成， 人员素质难以在工作中得到提升, 不能紧跟时代步伐, 满足与时俱进的工作需求, 同时长期 从事单一且机械性的工作难以使员工在工作中获得成就感、满足感，降低员工积极性。

3、薪酬制度单一，待遇留人不到位。一项合理的薪酬制度需要对员工岗位进行合理评估 以及员工薪酬进行内外部均衡分析, 进而设计合理的薪酬结构和确定薪酬的范围、等级, 最 后制定薪酬的适时调整措施。而当前非在编职工的薪酬制定过程简单, 薪酬偏低且结构单一, 与社会同行业职工的薪酬相比差距较大，得不到最起码的物质保障。

4、缺乏有效的激励机制和约束机制，难以营造良性竞争氛围。当前高校后勤在管理上存 在企业管理与高校行政管理两种模式, 主要是模拟企业化运行模式, 因此不可避免地在激励 机制方面存在先天性的缺陷, 没有系统性的激励政策、绩效评价尚未完善、竞争上岗, 同岗 同酬难以落实。

\section{2 人员结构不合理, 人力梯队创建困难}

1、基层队伍稳定性差。后勤基层员工主要分布在维修、保洁、绿化、食堂等一线岗位, 做着许多 “脏、苦、累” 的服务保障工作, 工作量大、工作环境差、工资水平低于社会同行 业水平, 同时当前大城市生活成本提高, 非在编职工得不到起码的物质保障, 流动性大和招 工困难成为外聘职工队伍不稳定的一大难题。

2、管理层流动性差。高校后勤仍存在计划经济的影子，管理层多为在编员工任职，存在 身份壁垒, 外聘员工难以进入。同时后勤岗位与教学、科研岗位相比处于从属地位, 相对 “低 端” 和 “弱势”, 没有学校政策扶持, 发展前景受限, 校内或者其他社会人才不愿进入后勤 任职。因此对内杰出人才难以脱颖而出, “造血” 功能差; 对外更没有诱人的条件设置, “换 血” 能力低, 致使管理层人才更新缓慢。

3、业务骨干综合素质参差不齐。主要表现为管理队伍整体素质有待提高，人才分配不均 衡。其整体平均学历层次明显低于学校其他管理队伍, 相当多的管理人员没有经过系统培训, 管理经验和管理手段都缺乏系统性和科学性。并且仅有的少数拥有高学历或者高级职称的人 员多分配在机关科室以及中心行政部门, 并不从事一线工作, 工作效率以及质量难以保证。

\section{3. 加强高校后勤非在编员工管理的途径}

高质量的后勤管理与高校教学、科研一样, 不仅是高校教科研工作的保障, 更是高校工 作中的重要组成部分。对于非在编职工管理存在的问题, 应针对不同的管理人群实施不同的 有效的管理方法 ${ }^{[2]}$, 以制度完善为前提, 以有效激励为保障, 公平、公开、公正地开展定岗 定编工作。

\section{1 构建与岗位相配套的规章制度体系}

定岗定编必须与薪酬体系改革交相呼应, 淡化身份差异, 实现同岗同酬。在按照 “总量 控制, 结构优化” 的指导思想, 分步实施定岗定编, 挖潜增效的同时, 必须建立科学合理的 非在编员工薪酬体系, 细化现有工资档级, 按照人员资质、学历、工龄和历年考核结果, 适 当拉开工资差距, 并提高管理岗非在编员工待遇。在 “互联网 + ” 以及大数据迅速普及的时代, 工作、生活以及思维都迎来大的变革, 因此必须开发一套人力资源管理系统, 由传统的、落 
后的、手工统计的人力资源管理方式转向系统化、网络化、智能化管理方式，提高工作效率， 避免人为因素的干扰。通过将定岗定编与薪酬体系重新制度化改进, 实现 “人、岗、事” 三 者之间的合理匹配与待遇留人齐头并进，建立精干高效的后勤实体。

\section{2 完善能上能下、奖优罚劣的激励奖励机制}

有效的激励会激发员工的活力，促使他们的工作更加主动，更加积极，更加有责任心。 对于现有员工, 通过激励将奖罚与工作业绩挂钩, 在职工之间营造良性竞争氛围, 可以使员 工的个人价值和单位目标有机结合起来, ${ }^{[3]}$ 从而实现奖励先进鞭策后进的效果, 保证定岗定 编的实现良性循环。在实践中, 除了综合运用形式各异的精神激励和物质奖励外, 更重要的 还是在畅通非在编员工的上升渠道动脑筋、下功夫，利用和挖掘好现有政策，使那些想干事、 能干事、干成事的员工都能有属于自己的职业发展规划, 增强他们的归属感和成就感, 切实 做到待遇留人、事业留人。

对于急需人才岗位, 可择优选聘应届毕业生充实管理和技术队伍, 或通过人事代理吸引 社会人才和技术管理团队; 通过向学校申请政策上的倾斜, 创造一个良好的工作环境, 吸引 校内各类人员加盟。大量引进优质人才不仅能够加强人才储备和使用, 还可以优化员工队伍 的层次和结构, 从而提升后勤员工队伍的整体水平。

\section{3 充分调动集团和中心两级的积极性}

集团层面只制定一般性规章，具体规则交由各科室、中心按照部门工作实际权宜实施。 首先后勤各部门按照工作职能, 重新梳理本部门业务流程、服务流程和管理流程, 设定岗位, 明晰岗位职责, 制定岗位说明书, 提出定岗定编以及人员聘任办法, 然后交由后勤集团层面 审核。集团与各部门以 “三上三下” 为原则, 进行多次硡商与探讨并同时进行岗位评价与岗 位确定, 明确各部门岗位管理序列、岗位职数、岗位系数等定岗定编情况, 明晰权、责、利, 做好人员聘任的前期工作。之后的岗位聘任可根据定岗定编情况以及岗位职责要求, 实行双 向选择和竞岗的形式进行聘用。通过人员聘任环节达到各类人员合理的比例关系和合理的层 次结构, 使员工群体组合最优化, 以发挥最大效能。

\section{4. 岗位管理过程中应该注意的几个问题}

高校后勤岗位管理首先要依据是后勤本身的发展战略或业务目标, 高校后勤在特定的时 期内, 要完成什么样的目标, 这是后勤一切工作的中心。 ${ }^{[4]}$ 为确保定岗定编的顺利实施, 并 最终达到预期的效果, 具体工作中还要坚持以下几个原则:

\section{1 尊重传统与兼顾未来原则}

通盘考虑, 既立足于当前, 又兼顾后勤未来发展, 把定编定岗与各部门实际工作需要结 合起来, 坚决防止滥设、多设、虚设岗位。具体来说, 可以在现有基础上, 岗位设置、人员 编制增减等不进行大规模变动, 保持后勤人力资源管理的稳定性。但同时要明确集团发展战 略目标与主要任务, 以 “事” 设岗、因 “事” 择人, 坚持高标准、高要求, 要善用人、选对 人、培育人, 做好后勤人才的梯队建设, 建立起一支与后勤长远发展需要相适应的职工队伍。

\section{2 集中管理与事权下放相结合原则}

集团统筹, 部门自主。后勤通过制定统一定岗定编办法对各部门进行原则性指导, 各单 位在遵守总体原则的前提下根据本部门实际情况制定相应的具体实施方案, 并报备后勤批准 后实施。具体来说对于后勤中上层及管理岗员工定岗定编的模式、方法、原则等由集团统一 制定实施。而对于一线员工, 可放权至各单位具体实施, 毕竟日后一线员工的管理使用和考 核还是由各单位具体操作。因此, 在集团审核批准了各单位的实施方案后, 在实施过程中只 
要不违背法律法规或学校用人规定, 集团不应进行过多干预。这样既为集团减负, 又使得定 岗定编工作更为切合实际，富有效率。

\section{3 多元化用工与挖潜增效相结合的原则}

用工多元化可以使后勤有限的资源得到最大限度的使用，通过定岗定编，结合目前管理、 技术水平和用工情况, 同时参照行业标准和兄弟院校做法, 可在不同的岗位采用外包、返聘、 实习生、季节工、小时工等多元化用工模式, 充分利用现有的人力、物力。定岗定编的目的 就是为了挖潜增效, 而多元化用工可以缓解 “短期工作、长期用人” 而造成的人员闲置与资 源浪费, 既能快速有效的解决临时性问题, 又不给集团增加新的负担, 使集团用人更富弹性, 从而精简机构与人员，提高工作效率。

\section{4 最少岗位数与人文关怀并重原则}

岗位设置要保证岗位工作量的饱满, 既不能事务繁重造成岗位人力的透支, 又不能工作 清闲, 人浮于事。所以对于专业性较强、事务繁琐的事务可单独设岗, 而对于相通性、关联 性较强, 工作简易的事务可合并设岗, 减少交易成本, 增强统筹协作能力, 以最少的岗位数, 最大限度的满足后勤工作需要。当然, 定岗定编并不是趁机裁员, 而主要采取全员竞聘的方 式，让能者上、平者让、庸者下，营造竞争氛围，激发员工潜力。

高校作为公益性的事业单位, 并不能一味地强调效益, 还要发挥工会等群团组织的作用, 注重人文关怀以及职工合法权益的维护，做好岗位聘任的善后工作，合理分流相关人员。工 会应积极从思想以及实际工作和生活中关心非在编职工, 在深入一线广泛调研的基础上, 形 成切实可行的建议方案, 帮助非在编员工提高政治待遇、收入待遇和福利待遇, 增强非在编 员工的归属感和认同感。

\section{References}

[1] Qu Xianghua,Cai Chuyuan,Jiang Qiong. Adapting to "Double First-rate" Construction Needs and Optimizing the Management of University Logistics[J]. China Higher Education.pp.48-50,2016.

[2] Ji Yonghui,Zhang Caiyan. Analysis and Countermeasures on the Present Situation of Temporary Employee in University Logistics[J]. Journal of Zhejiang Shuren University.pp.69-74,2012.

[3] Wang Zirong. Research on Incentive Mechanism of Temporary Employee in University Logistics[J]. Sichuan University of Arts and Science Journal.pp.61-64,2017.

[4] Gu Zhengjun, Chen Yun. Research on human resources management in the socialization reform of university's logistics[J]. Nanjing Agricultural University.pp.19-22,2005. 